\title{
Potential impacts of Antarctic bioprospecting and associated commercial activities upon Antarctic science and scientists
}

\author{
Kevin A. Hughes*, Paul D. Bridge \\ British Antarctic Survey, Natural Environment Research Council, High Cross, Madingley Road, Cambridge CB3 0ET, UK
}

\begin{abstract}
The Antarctic Treaty and associated agreements have little to say specifically on bioprospecting activities within the Treaty area. Consequently, Antarctic bioprospecting has elicited much debate within the Antarctic community, particularly on issues such as benefit sharing between Antarctic Treaty parties, the free availability of scientific data originating in Antarctica and the potential environmental impacts. However, the effect of a further increase in Antarctic bioprospecting activity on Antarctic science, and biologists in particular, in the absence of internationally agreed regulation may deserve further consideration. In this paper we discuss some of the potential issues bioprospecting may present to the Antarctic science community including science funding, personal gain, international scientific collaboration and interactions with industrial partners.
\end{abstract}

KEY WORDS: Antarctica $\cdot$ Bioprospecting $\cdot$ Science $\cdot$ Scientist $\cdot$ Collaboration $\cdot$ Funding $\cdot$ Industry Antarctic Treaty

Resale or republication not permitted without written consent of the publisher

\section{INTRODUCTION}

The Antarctic Treaty, entered into force in 1961 (Antarctic Treaty System [ATS] 2009a), was created to preserve Antarctica as a continent dedicated to science and peace. Since then, a series of legal instruments have come into force to control commercialisation of Antarctica's resources. These include the Convention on the Conservation of Antarctic Marine Living Resources (CCAMLR) (ATS 2009c) which regulates the harvesting of living resources (mainly fish and krill) within the Southern Ocean, the Convention for the Conservation of Antarctic Seals (CCAS) (ATS 2009b) which controls sealing (although none has occurred since the Convention was signed) and the Protocol on Environmental Protection to the Antarctic Treaty (ATS 2009d), which prohibits mining of Antarctica's mineral resources. In recent years, biotechnology has become increasingly sophisticated, and interest has increased in exploiting Antarctica's marine and terrestrial biodiversity with several Antarctic Treaty nations undertaking bioprospecting activities (Lohan \& Johnston, 2005,
Herber 2006). Unlike fishing, sealing and minerals extraction, so far there has been no formal agreement on the regulation of bioprospecting in Antarctica.

The term 'bioprospecting' has many different definitions, though there is no single internationally accepted definition of bioprospecting (ATCM 2009c). Here we shall use the definition of Rogan-Finnemore (2005, p. 3) who describes bioprospecting as 'a range of activities associated with the search for a novel biodiversity, whose component parts may be utilised in a product or process and developed for commercialisation'. However, no legal definition has been agreed under the ATS due to the complexities of the issue. For example, while clearly directed sampling programmes would be widely accepted as bioprospecting, the screening of individual genes in previously collected materials may not be. Modern technology for generating genomic libraries from an environmental sample allows for gene screening, and possibly commercial development, in the absence of an isolated organism.

Looking to the future, there is a need to clarify what constitutes bioprospecting, its likely environmental 
impacts and how it fits with the legislation within the Antarctic Treaty. Bioprospecting has been considered within the ATS on several occasions (see Lohan \& Johnston 2005), and it is likely that it will remain a topic of debate for many years to come, as there may be disagreement between Antarctic Treaty parties on many issues, and in particular, benefit sharing (ATCM 2009a).

Territories in the sub-Antarctic area north of $60^{\circ} \mathrm{S}$ are subject to various national jurisdictions, and benefit-sharing arrangements, such as those contained in the Convention on Biological Diversity (CBD) (CBD 2009), will generally apply. The CBD is ratified by national governments, and so applies to all terrestrial and marine environments under national jurisdiction. There are current movements to incorporate international waters within $\mathrm{CBD}$, and these include the establishment of marine protected areas (see World Wildlife Fund [WWF] 2008). The CBD as a nationally constituted treaty cannot currently be implemented within the Antarctic Treaty System south of $60^{\circ} \mathrm{S}$, where territorial claims are suspended. Until international agreement is reached, bioprospecting activities will be controlled by the regulations and strategic requirements of national governments, including their potentially different interpretation of the existing legislation within the Antarctic Treaty (ATCM 2009b).

In this paper, we discuss some of the possible consequences of Antarctic bioprospecting on the biologists working in the region, should bioprospecting activities take on a greater importance in the absence of internationally agreed regulation. We have attempted to present a wide spectrum of potential impacts, ethical issues and ramifications of bioprospecting, which, it is hoped, will be a useful point of reference for policy makers in the on-going debate.

\section{ANTARCTIC SCIENTISTS}

Antarctic biological scientists are a diverse group, with laboratories distributed globally (Scientific Committee on Antarctic Research [SCAR]; www.scar.org). Individual scientists may be technique-centred (e.g. molecular or biochemical techniques) while others may specialise in the study of a restricted range of organisms (e.g. tardigrades, lichens or marine phytoplankton) with discipline-specific expertise developed over many years, if not decades. Some biologists may work exclusively on Antarctic topics, whilst others may see Antarctic projects as only part of their overall research. The majority are employed in the national public sector and may be part of a dedicated national Antarctic programme (e.g. the British Antarctic Survey [BAS] or Australian Antarctic Division), or work within a non-Antarctic-focussed government research institute or university. Inevitably, there will be a wide spectrum of both interest in bioprospecting/commercialisation and, perhaps more importantly, applicability of an individual scientist's expertise to engage in bioprospecting activities. Biologists, perhaps within the same institute, may be divided between those who can undertake commercialisation following bioprospecting activities, due to their molecular or biochemical backgrounds, and those specialising in ecology and taxonomy for whom sample collection for bioprospecting may be possible, but the value-added stages of screening and generation of leads are not. Early career scientists may be more flexible in the lines of research they pursue (either purely scientific or for commercial reasons) and may be more familiar with the use of recently developed biotechnology. More experienced biologists may more easily identify potential commercialisation opportunities and may have amassed both a substantial quantity and diversity of biological material of Antarctic origin during their careers which could be screened relatively easily for potentially useful biomolecules.

\section{SCIENTIFIC VERSUS COMMERCIAL DIRECTION}

Although the term 'bioprospecting' may suggest the deliberate collection of organisms for screening for possible commercialisation, and while this has historically occurred world-wide, it is unclear as to what extent such activities have occurred in the Antarctic (see Johnstone \& Lohan 2005, United Nations University - Institute of Advanced Studies [UNU-IAS] 2010). There are 2 more common ways through which Antarctic biological material has been made available (see Table 1, rows $2 \& 3$ ). One is through the screening and utilisation of 'historic' material that was originally collected for earlier scientific projects, and has subsequently been maintained. One example of this are the low temperature lipases (e.g. Novozym 435) now commercially produced from genes of Pseudozyma antarctica (synonym Candida antarctica), a yeast that was originally isolated and made available through culture collections in the 1960s (Sugiyama et al. 1967). There are no comprehensive listings of how many Antarctic biological specimens are currently available through public access collections. Most major culture collections and herbaria contain some Antarctic material, and some national Antarctic programmes also maintain collections. From our personal experience, we would estimate that $>10000$ microbial cultures may be held in international, national and institutional culture collections, and there are likely to be at least 80000 dried plant and lichen specimens in herbaria world- 
wide. However, it is often difficult to find out the origin of a particular organism (particularly a microorganism) once it is sourced from a culture collection, and this information is often not included in patent applications making it is difficult to evaluate the true amount of Antarctic bioprospecting. A second and probably more common route for obtaining Antarctic materials for screening programmes is through commercial partnerships with particular scientific projects, most notably biodiversity surveys and monitoring. This approach has been used extensively both world-wide and in the Antarctic (Laybourn-Parry \& Vincent 2008), and in some instances has resulted in some large-scale screening programmes (e.g. Marinelli et al. 2004).

From an ethical standpoint, both the use of 'historic' material and the scientific partnership could be seen as making the best use or recycling of materials collected for fundamental science. For example, the UK's Natural Environment Research Council has been investigating the commercialisation potential of its Antarctic microbial collection (BAS 2010). It could be argued that such activities are not strictly bioprospecting, as the original driver for the sampling was the science project. In developing the partnership approach, there is a possibility for the sampling to be influenced by the inclusion of sites or niches that could be expected to yield microbes with commercially exploitable properties. There are clearly differences between opportunistic, informed and directed sampling, but at what point these can be said to constitute 'bioprospecting' is not clear.

\section{FUNDING}

Despite their diverse scientific background, all Antarctic scientists need funds to carry out their research. In an era of economic uncertainty, scientists of all disciplines are under increasing pressure to generate income to fund their research, contribute to their salaries and support their host institutes. Many governments want their Antarctic scientists to perform excellent research as well as providing a political presence on the continent (e.g. a stated aim of the British Antarctic Survey is to 'sustain for the UK an active and influential Antartic regional presence and a leadership role in Antarctic affairs' (BAS 2009). However, increasingly, scientists are asked also to consider how their work might be commercialised for the financial benefit of the nation. Antarctic Treaty nation governments spend considerable sums funding Antarctic science. Justifiably, they want to get the maximum benefit from their investment not only in terms of increasing knowledge of Antarctica, but also through the use of Antarctica's biological resources to benefit their populations both financially and in terms of quality of life through discoveries of use to the agrochemical, pharma- ceutical, cosmeceutical, and nutraceutical industries. This change in focus is starting to be reflected in the wider research environment, for example, the UK has recently submitted for consultation a new system for assessing the quality of research in UK higher education institutions (HEIs) called the Research Excellence Framework, with a key characteristic of research excellence including, amongst other criteria, that it delivers demonstrable benefits to the economy (Higher Education Funding Council for England [HEFCE] 2009). A simple redirection of funding towards projects better suited for commercial development could result in some reduction or loss of other areas of biological science. More specifically, this could impact upon our understanding of Antarctic ecosystems as a whole. It is to be hoped that both potential commercial development and scientific direction can be included in single projects, in a similar way to the combined biodiversity/biological activity approach that has been successful in other areas (e.g. Kelley et al. 2003).

\section{PERSONAL GAIN}

A scientist's impact can be assessed by the number of grants won, peer-reviewed papers published, and patents and commercialisation opportunities that have arisen from his/her work. A substantial additional incentive for some scientists may be the personal financial gains that may come about if bioprospecting activities yield a discovery with mainstream commercial applications. For most Antarctic biologists, the prospect of increasing their personal wealth through their Antarctic research may be an unfamiliar concept; however, once successful commercialisation is achieved by colleagues, it may become an accepted focus for many scientists in addition to their usual role. How benefits are distributed could generate tension between scientists, who previously enjoyed close collaboration. For example, a taxonomist might supply biological material to a scientist specialising in proteomics, but may feel it necessary to have a formal agreement to ensure they receive a fair share of any commercial benefits resulting from any subsequent research using that material. Ultimately, this may formalise the relationship between scientists and the sharing of biological materials. Although such arrangements are well established at an institutional level, such as in material transfer and intellectual property rights (IPR) agreements, the mechanism for benefit sharing at an individual level is not clear, but would need to be negotiated between individual scientists, the industrial partner and host institute(s). Scientists may be at a disadvantage during these negotiations if they have little experience of such contracts. 


\section{INTERNATIONAL COLLABORATION}

Antarctic biologists rarely work in isolation, and often collaborate with scientists from various nations. Formal groups exist such as Evolution and Biodiversity in the Antarctic (EBA; www.eba.aq), which is the flagship scientific research programme of SCAR's Standing Scientific Group on Life Sciences (SSG-LS), but on a smaller scale, like-minded scientists from different nations often collaborate on a less formal level. How bioprospecting fits within this framework is difficult to assess. As a consequence of the complexities of differing domestic legislation, variations in interpretations of Antarctic legislation and international intellectual property assignment and patenting law, it may be difficult for an international collaboration of scientists to successfully commercialise a discovery originating from Antarctica (Johnston \& Lohan 2005). Nevertheless, models for shared IPR, and other benefit sharing agreements have been developed successfully for other international forums, such as European Union (EU) framework programmes, and these may help in providing models for the Antarctic. In practice, much will depend on the conditions imposed by the funding agency with regard to ultimate ownership of IPR. There is a potential conflict between the academic principle of peer-reviewed publication, and the commercial/industrial requirement to limit any prior disclosure before patenting or licensing arrangements are made (see 'Interaction with industrial partners'). While this is now widely recognised by institutions and authorities, it may reduce the interaction/trust among individual scientists that traditionally exists within the Antarctic scientific community and which has been a cornerstone of Antarctic research in the past and a founding principle of the Antarctic Treaty.

Article III of the Antarctic Treaty states that to the greatest extent feasible and practicable: [...] scientific observations and results from Antarctica shall be exchanged and made freely available'. If an applied biological process is published in the peer-reviewed literature, the opportunity for patenting and development by an industrial partner for economic benefit is almost certainly past. Widespread bioprospecting activities involving Antarctica Treaty nations and industry could significantly delay the dissemination of information useful to other scientists, and if some organisms have commercial applications, their properties may be kept confidential for many years (ATCM 2009b). For example, a microbiologist undertaking biodiversity screening of Antarctic soils may be reluctant to disseminate some of his/her results until they have been assessed for industrial applications. Antarctic biologists may develop 'pre-fieldwork' agreements with industrial partners to allow them first refusal for commercialisation of any leads discovered. The confidentiality clauses associated with these pre-fieldwork agreements may put ongoing scientific openness and collaboration at risk (SCAR 2009). It is unclear how scientists are meant to resolve the conflicting requirements of sharing their data with fellow scientists (as described by the Antarctic Treaty) and the need for confidentiality when commercialisation and patenting processes involve Antarctic biota. In addition, deposition of Antarctic specimen to recognised national Antarctic herbaria, microbial culture or invertebrate specimen collections may be delayed or avoided as scientists become more concerned about protecting future intellectual property rights. Conversely, patent depositions are usually publicly available and so could be said to conform 'in letter' to Article III. Many scientific studies publish their results in some form of sequence, reflecting the rate of analysis, interpretation and relevance of the data. A similar approach may be suitable for more commercially focused studies, allowing disclosure of some of the background or associated science. In some instances, this may constitute the bulk of the data collected. It should be remembered that the IPR or patent component is not the organism itself, but the process that uses the organism, or the methodology for detecting, extracting or adapting its properties. This is often likely to arise from work at the 'home' laboratory and may be significantly removed from the original Antarctic specimen.

Article III (Antarctic Treaty 1959) also states that 'to the greatest extent feasible and practicable: [...] scientific personnel shall be exchanged in Antarctica between expeditions and stations'. Levels of endemism may be high across many biological groups within the distinct biogeographic zones of Antarctica (Vincent 2000, Convey \& Stevens 2007), although some taxa appear to be globally distributed (Jungblut et al. 2010). National logistic operators with research facilities in one zone may be reluctant to host visits by scientists of different nationalities, in case they undertake biological sampling for bioprospecting purposes. This may lead to commercialisation agreements between national operators, before exchange of scientists can occur. This situation is less likely with microbes where very local and micro-climate defined conditions are likely to be more significant than broader biogeographic factors (Bridge et al. 2008, Bridge \& Newsham 2009).

The practice of supporting 'non-nationals' through national programmes will undoubtedly lead to complications in determining subsequent ownership of IPR. While these may be dealt with through Letters or Memoranda of Understanding and IPR agreements, the level of complexity will grow quickly if multiple partners, funding sources and third parties are involved. 


\section{INTERACTION WITH INDUSTRIAL PARTNERS}

As discussed earlier, biologists may be under increasing pressure from their employers to commercialise their discoveries and actively seek industrial partners. However, the relationship between Antarctic scientists, industrial collaborator and national logistics organisation may be a complex one and lead to ethical issues, including conflicts of interest between science and income generation. Table 1 shows a range of different scenarios by which commercial partners may access Antarctic biological material, each with a different level of input by Antarctic scientists. Involving experienced Antarctic biologists in any pre-planned bioprospecting activity is likely to enhance the probability of success, as often they can recommend sampling locations, effective sampling techniques and times, as well as possessing knowledge of previous scientific activity in an area. In addition, the involvement of a specialist in the taxa being sampled can provide informed sampling based on known functional and ecological properties. Although environmental protection is the responsibility of everyone entering Antarctica (ATS 2009d), by default, it may become the task of experienced Antarctic scientists in the field, to ensure that the sampled Antarctic habitat is not damaged by bioprospecting (Tin et al. 2009). In theory, the impact of planned bioprospecting activities should be assessed as Antarctic Treaty nations are obliged to undertake environmental impact assessments (EIAs) for all activities within the Treaty Area (south of latitude $60^{\circ} \mathrm{S}$ ) (ATCM 2009b). Some Antarctic scientists take, what they consider to be, the pragmatic view that bioprospecting may become an important element for the conservation of Antarctica; if Antarctica is viewed as a source of biodiversity which generates economic benefits, then there may be a greater, on-going will by the Antarctic community to reduce the rate of loss of habitat and biological distinctiveness present in the region.
Some Antarctic Treaty nations may have little access to sophisticated molecular or biochemical techniques, and if they are to participate in bioprospecting activities, they may be limited to facilitating sample collection, with all the screening for useful biomolecules and associated research and development undertaken by an international industrial partner. Once the scientists from the Antarctic Treaty nation hand the samples over to the industrial partner it may be difficult for the Antarctic Treaty nations to monitor scientific developments. One solution might be that scientists from developed countries assist their colleagues from developing countries with more sophisticated molecular biology techniques, which might also constitute a type of benefit-sharing arrangement between scientists.

The stage at which industrial partners get involved in bioprospecting and commercialisation of Antarctic material may be changing. In the past, research scientists have, in the course of their normal work, discovered some interesting phenomenon, undertaken experiments to clarify their findings and then, following consultation with commercialisation experts, found a commercial partner. In short, chance and the scientist's expertise and enthusiasm have been the main drivers for commercialisation. However, more recently, commercialisation opportunities from Antarctic material have resulted from specific searches for biomolecules in likely habitats, followed by screening and further research into promising candidates. If commercialisation of Antarctic material is seen to be profitable by industry, then there may be greater sampling for bioprospecting within Antarctica.

\section{CONCLUSIONS}

It is conceivable that once the business world is entered, with potentially significant financial gain in prospect, the subtleties of the Antarctic Treaty may be quickly relegated to the background, and the boundaries of what bioprospecting activities are permitted un-

Table 1. Potential relationships between Antarctic scientists and commercial organisations, with the scientist's degree of involvement shown. In this context, Antarctic scientists include those with a track record of research in Antarctica working for national government research institutes or universities

Scientific / commercial relationship

Scientist's involvement

Antarctic scientists offering an unexpected scientific discovery with an obvious industrial application to a company for commercial development

Antarctic scientists offering biological material or organisms previously sampled or isolated during non-commercial work for commercial screening

Antarctic scientists undertaking sampling of Antarctic biological material for commercial applications alongside fieldwork for existing scientific research

Antarctic Treaty nation providing logistical support for a commercial sampling expeditions (little or no involvement by Antarctic Scientists) 
der existing legal frameworks may be stretched. The Antarctic Treaty Consultative Meeting parties and SCAR may need to extend the debate on bioprospecting to scientists at all levels so that all may understand the benefits and difficulties associated with bioprospecting. Antarctic scientists, including SCAR, are one step removed from the political concerns that exist between Antarctic Treaty nations, and as such may be able to give a more measured view on the influences of bioprospecting in Antarctica. It is hoped that any resolution of the bioprospecting issue may have no negative impact upon existing scientific research, but rather support Antarctic biological science and create more opportunities for exploitation of existing scientific research.

Acknowledgements. We acknowledge the input of the Antarctic biologists who shared their perspectives and opinions with us during discussions relating to the bioprospecting issue, and thank Prof. W. Vincent and 2 other anonymous reviewers for their useful comments. This paper contributes to the British Antarctic Survey's Polar Science for Planet Earth programme (Environment Office - Long-Term Monitoring and Survey).

\section{LITERATURE CITED}

ATCM (Antarctic Treaty Consultative Meeting) (2009a) Belgium, Brazil, Bulgaria, Finland, France, Germany, the Netherlands, Sweden: The Antarctic Biological Prospecting Database. Working Paper 001. ATCM XXXII, 6-17th April 2009, Baltimore, MD

ATCM (2009b) Australia, New Zealand: Regulation of biological prospecting under the Antarctic Treaty System. Working Paper 018. ATCM XXXII, 6-17th April 2009, Baltimore, MD

ATCM (2009c) Sweden, Belgium, Finland, France, The Netherlands, Spain: concepts, terms and definitions, including a comparative analysis (biological prospecting). Information Paper 070. ATCM XXXII, 6-17th April 2009, Baltimore, MD

ATCM (2009d) Biological prospecting in the Antarctic: an update on the review by SCAR. Information Paper 065. ATCM XXXII, 6-17th April 2009, Baltimore, MD

ATS (Antarctic Treaty System) (2009a) Antarctic Treaty. Washington (DC) 1959. Available at: www.ats.aq/documents/ats/treaty_original.pdf (Accessed: 13 October 2009)

ATS (Antarctic Treaty System) (2009b) Convention for the Conservation of Antarctic Seals. London 1972. Available at: www.ats.aq/documents/recatt/Att076_e.pdf (Accessed: 13 October 2009)

ATS (Antarctic Treaty System) (2009c) Convention on the Conservation of Antarctic Marine Living Resources. Canberra 1980. Available at www.ats.aq/documents/ats/ ccamlr_e.pdf, see also www.ccamlr.org (Accessed: 13 October 2009)

ATS (2009d) Protocol on Environmental Protection to the Antarctic Treaty. Madrid 1991. Available at: www.ats.aq/ documents/recatt/006_e.pdf (Accessed: 13 October 2009)

BAS (British Antarctic Survey) (2009) Corporate Aims. Available at: www.antarctica.ac.uk/about_bas/corporate_aims/ index.php (Accessed: 12 October 2009)

BAS (2010) Biotechnology from Antarctica. Available at www. antarctica.ac.uk/biotech/ (Accessed: 25 February 2010)

Bridge PD, Newsham KK (2009) Soil fungal community com-

Editorial responsibility: David Walton,

Cambridge, UK position at Mars Oasis, a southern maritime Antarctic site, assessed by PCR amplification and cloning. Fungal Ecol 2:66-74

Bridge PD, Spooner BM, Roberts PJ (2008) Non-lichenized fungi from the Antarctic region. Mycotaxon 106:485-490

CBD (Convention on Biological Diversity) (2009) About the Convention. Available at www.cbd.int/convention/about. shtml (Accessed: 24 November 2009)

Convey P, Stevens MI (2007) Antarctic Biodiversity. Science 317:1877-1878

- Herber B (2006) Bioprospecting in Antarctica: the search for a policy regime. Polar Rec 42:139-146

HEFCE (Higher Education Funding Council for England) (2009) Research Excellence Framework. Available at www.hefce.ac.uk/Research/ref/ (Accessed: 13 October 2009)

Johnston S, Lohan D (2005) Existing activities, policies and emerging issues for the Antarctic Treaty System. In: Hemmings AD, Rogan-Finnemore M (eds) Antarctic Bioprospecting. Gateway Antarctica Special Publication Series, No. 0501, Christchurch, p 130-206

Jungblut AD, Lovejoy C, Vincent W (2010) Global distribution of cyanobacterial ecotypes in the cold biosphere. ISME J $4: 191-202$

Kelley J, Cannon P, Simmonds M, Pingal R, Simmons C (2003) The Iwokrama programme: an approach to the sustainable exploitation of genetic resources. In: Lima N, Smith D (eds) Biological resource centres and the use of microbes. Micoteca da Universidade do Minnho, Braga, p 185-195

Laybourn-Parry J, Vincent W (2008). Future directions in polar limnology. In: Vincent W, Laybourn-Parry J (eds) Polar lakes and rivers: limnology of Arctic and Antarctic aquatic ecosystems. Oxford University Press, Oxford, p 307-316

Lohan D, Johnston S (2005) United Nations University - Institute of Advanced Studies (UNU-IAS) Report. Bioprospecting in Antarctica. Available at: www.ias.unu.edu/binaries2/antarctic_bioprospecting.pdf (Accessed: 6 October 2009)

Marinelli F, Brunati M, Sponga F, Ciciliato I and others (2004) Biotechnological exploitation of heterotrophic bacteria and filamentous fungi isolated from benthic mats of Antarctic lakes. In Kurtböke I, Swings J (eds) Microbial genetic resources and biodiscovery. World Federation of Culture Collections, Queensland Complete Printig Services, Queensland, Australia, p 163-184

Rogan-Finnemore M (2005) Setting the scene. In: Hemmings $\mathrm{AD}$, Rogan-Finnemore M (eds) Antarctic bioprospecting. Gateway Antarctica Special Publication Series, No. 0501, Christchurch, p 1-9

Sugiyama J, Sugiyama Y, Iizuka H, Torii T (1967) Report of the Japanese Summer Parties in Dry Valleys, Victoria Land, 1963-1965. IV. Mycological Studies of the Antarctic Fungi. Part. 2. Mycoflora of Lake Vanda, an ice-free lake. Antarct Rec (Tokyo) 28:23-32

Tin T, Fleming ZL, Hughes KA, Ainley DG and others (2009) Impacts of local human activities on the Antarctic environment. Antarct Sci 21:3-33

UNU-IAS (United Nations University - Institute of Advanced Studies)(2010) Bioprospecting information resource. Available at www.bioprospector.org/bioprospector/ (Accessed: 25 February 2010)

Vincent W (2000) Evolutionary origins of Antarctic microbiota: invasion, selection and endemism. Antarct Sci 12:374-385

WWF (World Wildlife Fund) (2008) Steps finally taken to protect the high seas. WWF Bull 15:1

Submitted: December 16, 2009; Accepted: March 19, 2010

Proofs received from author(s): April 4, 2010 